\title{
MELHORAMENTO DO TRIGO: XVIII. COMPORTAMENTO DE LINHAGENS EM CINCD REGIÕES PAULISTAS ( $\left.{ }^{1}\right)$
}

\author{
CARLOS EDUARDO DE OLIVEIRA CAMARGO $(2,6)$, JOÃO CARLOS FELÍCIO $(2,6)$, \\ ANTONIO WILSON PENTEADO FERREIRA FILHC (2), JOSÉ GUILHERME \\ DE FREITAS $(2,6)$, BENEDITO DE CAMARGO BARROS $(3,6)$, JAIRO LOPES \\ DE CASTRO $(4,6)$, ARMANDO PETTINELLI JÚNIOR (5) \\ Q LAÉRCIO SOARES ROCHA JÚNIOR (2)
}

\section{RESUMO}

Avaliaram-se vinte $e$ duas linhagens e três cultivares de trigo em ensaios instalados em cinco regiōes paulistas, em 1984-86, analisando-se os seguintes parâmetros: rendimento de grãos, altura de plantas, cicio, em dias, da emergência ao florescimento e da emergência à maturação, porcentagem de plantas acamadas, comprimento da espiga, número de grãos por espiga e por espigueta, número de espiguetas por espiga, peso de cem grãos, resistência à ferrugem-do-colmo e da-folha em condições de campo e de casa de vegetação, resistência à helmintosporiose e ao ó́dio em condições de campo. Em laboratório, foram realizados estudos da tolerância

(1) Com verba suplementar do Acordo do Trigo entre as Cooperativas de Produtores Rurais do Vale do Paranapanema e a Secretaria da Agricultura, através do Instituto Agronómico. Recebido para publicação em 30 de dezembro de 1987 e aceito em 23 de agosto de 1988.

(2) Seção de Arroz e Cereais de Inverno, Instituto Agronômico (IAC), Caixa Postal 28, 13001 Campinas, $\mathrm{SP}$.

(3) Seção de Doenças das Plantas Alimentícias Básicas e Olerícolas, Instituto Biológico.

(4) Estação Experimental de Capão Bonito, IAC.

(5) Estação Experimental de Tatui, IAC.

(6). Com bolsa de pesquisa do CNPq. 
ao aluminio, em soluções nutritivas. Em sequeiro, nos ensaios conduzidos em Capão Bonito e no Vale do Paranapanema (Maracaí e Cruzália), destacaram-se, quanto à produção de grãos, respectivamente, o cultivar $\mathrm{BH}-1146$ e a linhagem 12. As linhagens 4, 9 e 13, em Campinas, e a 8, em Tatui, evidenciaram alta produção de grãos em condição de irrigação por aspersão. Na média de nove experimentos, destacaram-se em produção de grãos, por ordem decrescente, o cultivar $\mathrm{BH}-1146$ e as linhagens $13,20 \mathrm{e}$ 14. As linhagens 2, 7, 8, 17 e 18 e o 'Alondra-S-46' mostraram plantas significativamente mais baixas que o ' $\mathrm{BH}-1146$ ' e 'IAC-5'. As linhagens 7 e 8 e o cultivar Alondra-S-46 mostraram 'resistência às seis raças e as linhagens 17 e 18 a cinco raças testadas do agente causal de ferrugem-do-colmo em estádio de plântula, em casa de vegetação. Em campo, no estádio de planta adulta, apresentaram menor área infectada por essa doença as linhagens 1 , $2,7,8,12$ e 17 e o cultivar Alondra-S-46. Nas mesmas condiçōes, as linhagens $1,5,8$ e 18 exibiram menor área infectada por ferrugem-da-folha. As linhagens $11,12,13,19,20$ e 21 e o cultivar $\mathrm{BH}-1146$ mostraram tolerância à presença de $10 \mathrm{mg} /$ litro de $\mathrm{Al}^{3+}$ na solução nutritiva.

Termos de Indexação: trigo, Tritıcum aestivum L., cultivares, linhagens, produção de grãos, altura das plantas, ferrugem-do-colmo, ferrugem-da-folha, tolerância, toxicidade de alumínio.

\section{INTRODUÇÃO}

A área cultivada com trigo no Estado de São Paulo, em 1972, era de 25.000ha, alcançando, em 1986, 203.000ha, porém a produtividade somente atingiu $2.000 \mathrm{~kg} / \mathrm{ha}$ em 1985, com uma produçāo total de 282.000 toneladas de grãos. A produtividade média (1.843 kg/ha) obtida no Estado de São Paulo em 1985-86 foi superior à verificada no Rio Grande do Sul, no mesmo período $(1.265 \mathrm{~kg} / \mathrm{ha})$ e equivalente à do Paraná $(1.807 \mathrm{~kg} / \mathrm{ha})$. A produtividade paulista foi superior, no referido período, à observada na Rússia $(1.650 \mathrm{~kg} / \mathrm{ha})$, Canadá (1.770 kg/ha). Argentina (1.610 kg/ha) e Austrália (1.370 kg/ha), que estão entre os maiores produtores mundiais desse cereal. Por outro lado, a Europa Oriental e a Comunidade Européia apresentaram, no período 1985-86, produtividade média acima de 3.700 e $4.500 \mathrm{~kg} / \mathrm{ha}$ respectivamente (JUNQUEIRA \& SILVA, 1986).

Até o final da década de 70 , os cultivares recomendados para plantio no Brasil eram de porte alto, suscetiveis ao acamamento, com baixo potencial produtivo e baixa fertilidade das espigas, porém elevada adaptação aos solos ácidos, encontrados na maioria das regiōes triticolas brasileiras (ALCOVER, 1971; CAMARGO, 1972; FELíclO et al., 1983).

Os trigos mexicanos, originários da fonte de nanismo 'Norin 10 ' $\times$ 'Brevor 14' (HANSON et al., 1982), além do porte semi-anão, são portadores de palha forte, maior número de espiguetas férteis, maior perfilhamento, precocidade, res- 
postas à adubação, indice mais alto de colheita, insensibilidade à duracão do fotoperíodo e resistência às doenças. Dada, porém, elevada suscetibilidade à toxicidade de $\mathrm{Al}^{3+}$, esses cultivares somente são recomendados para as regiões brasileiras onde os solos e subsolos foram corrigidos, isto é, nāo apresentam teores de alumínio trocável ou solúvel (CAMARGO \& OLIVEIRA, 1981).

Recentemente foram lançados pelo instituto Agronômico os cultivares de trigo IAC-24 e IAC-60, de porte semi-anāo, alto potencial produtivo e com ampla adaptação aos solos ácidos devido à grande tolerância à toxicidade de $\mathrm{Al}^{3+}$. Esses cultivares foram obtidos a partir de seleções feitas nas populaçōes originárias de cruzamentos entre cultivares brasileiros, de porte alto, com cultivares semi-anōes de origem mexicana (CAMARGO \& FELÍCIO, 1986, e CAMARGO et al., 1985).

O presente trabalho teve por objetivo avaliar linhagens de trigo provenientes de cruzamentos efetuados no Instituto Agrônomico para selecionar novos germoplasmas de interesse ao programa de melhoramento genético para serem estudados nos ensaios finais visando a uma possivel recomendaçāo aos triticultores.

\section{MATERIAL E MÉTODQS}

Foram incluídas nos ensaios vinte e duas linhagens, cuja origem é descrita a seguir:

Linhagem 1 - Introduzida pelo Instituto Agronômico em 1969 (I-44529), proveniente do Instituto de Investigaçōes Agronômicas de Angola.

Linhagem 2 - Obtida por seleção do híbrido 320 , resultante do cruzamento entre o cultivar Bajio-67, introduzido do Centro Internacional de Melhoramento de Milho e Trigo (CIMMYT), México, e o hibrido entre os cultivares Sonora 63 (mexicano) e S-12 (do Rio Grande do Sul), seguido de um retrocruzamento para o 'Sonora-63'.

Linhagens 3, 4 e 5 - Selecionadas a partir do hibrido 1196, obtido do cruzamento entre o cultivar IAC-5 e a linhagem IRN 33-70, oriunda do Ensaio Internacional de Ferrugem do Trigo de Primavera (International Spring Wheat Rust Nursery, IRN), de 1970, conduzido pelo Instituto Biológico.

Linhagens 6, 7 e 8 - Obtidas por seleção do híbrido 1235, originário do cruzamento entre o cultivar Super $X$ (mexicano) e o híbrido entre uma linhagem restauradora de fertilidade (R) proveniente dos EUA e o 'IRN 471-63', seguido de quatro retrocruzamentos para o 'IRN 471-63'.

Linhagem 9 - Oriunda de seleções do híbrido 1491, obtido pelo cruzamento entre a linhagem IRN 526-63 (mexicana) e Pel 14933-64, introduzida do Instituto de Pesquisa e Experimentação Agropecuária do Sul (IPEAS), Pelotas, seguido de um retrocruzamento para o 'IRN 526-63'. 
Linhagem 10 - Selecionada a partir do híbrido 963, originário do cruzamento entre os cultivares Jaral-66 (mexicano) e BH-1146.

Linhagens 11, 12 e 13 - Obtidas por seleções do hibrido 1031, proveniente do cruzamento entre a linhagem IRN 641-70 e o cultivar BH-1146.

Linhagens 14 e 15 - Oriundas de seleções do hibrido 75, obtido pelo cruzamento entre o cultivar IAS-20 e a linhagem IRN 526-63.

Linhagem 16 - Selecionada a partir do híbrido 693, proveniente do cruzamento entre o cultivar IAS-51 e a linhagem IRN 597-70.

Linhagem 17 - Obtida por seleções do hibrido 885 , originário do cruzamento entre a linhagem IRN 484-70 e o cultivar BH-1146.

Linhagem 18 - Oriunda de seleçōes do hibrido 1231, proveniente do cruzamento entre a linhagem IRN 351-66 e o hibrido entre a linhagem E-641-R-243 (paraguaia) e o cultivar $\mathrm{BH}-1146$, seguido de um retrocruzamento para o 'BH-1146'

Linhagem 19 - Selecionada a partir do híbrido 1399, originário do cruzamento entre a linhagem PF 7064, oriunda do Rio Grande do Sul, e o cultivar $\mathrm{BH}-1146$.

Linhagens 20 e 21 - Obtidas por seleção do hibrido 296, resultante do cruzamento entre os cultivares Tobari-66 (mexicano) e BH-1146.

Linhagem 22 - Selecionada a partir do hibrido 1934, proveniente do cruzamento entre os cultivares Jupateco-73 (mexicano) e IAC-5.

Como controles, utilizaram-se os seguintes cultivares: $\mathrm{BH}-1146$ e IAC-5, de porte alto, suscetiveis ao agente causal da ferrugem-do-colmo, ciclo precoce, $\mathrm{e}$ tolerantes à toxicidade de $\mathrm{Al}^{3+}$, e Alondra-S-46, de porte semi-anão, resistente à ferrugem-do-colmo, ciclo médio a tardio e moderadamente sensivel à toxicidade de $A{ }^{3+}$. A origem desses cultivares é a seguinte:

'BH-1146' - Selecionado no Instituto Agronômico de Minas Gerais, Belo Horizonte, e proveniente do cruzamento 'Ponta Grossa l' x 'Frontana', híbrido esse que foi cruzado com o cultivar Mentana.

'IAC-5' - Obtido da progênie 17521, selecionada na Estaçāo Experimental de Capāo Bonito, em 1956, proveniente do cruzamento ('Frontana' $x$ 'Kenya') x 'Polissu'.

'Alondra-S-46' - Selecionado pelo CIMMYT, México, e introduzido pelo Centro Nacional de Pesquisa de Trigo, EMBRAPA, onde foi submetido a novo processo de seleção.

Utilizou-se o delineamento estatístico de blocos ao acaso, com três repetiçōes por local. Cada ensaio foi constituido de 75 parcelas, cada uma formada de cinco linhas de $3 \mathrm{~m}$ de comprimento, espaçadas de 0,20m. Deixou-se uma separação lateral de $0,60 \mathrm{~m}$ entre as parcelas. A semeadura foi feita na base de 80 sementes viáveis por metro de sulco, equivalendo a 1.200 por parcela, com uma área útil de colheita de $3 \mathrm{~m}^{2}$. 
Em 1984, instalaram-se quatro ensaios nos seguintes locais: Estações Experimentais de Tatuí e Capāo Bonito, Centro Experimental de Campinas e Fazenda Lagoa, em Maracai. Em 1985, três experimentos, nos seguintes locais: Estaçōes Experimentais de Capāo Bonito e Tatuí e Fazenda Santa Lúcia, em Cruzália. Dois ensaios foram semeados em 1986: na Estaçāo Experimental de Capão Bonito e no Centro Experimental de Campinas.

$\mathrm{Na}$ instaçaçāo dos ensaios, retiraram-se amostras compostas dos solos dos locais estudados, encontrando-se no quadro 1 os resultados analíticos obtidos.

Nos experimentos conduzidos em Campinas e Tatuí, irrigados por aspersão, e nos das demais localidades, sem irrigação, coletaram-se os seguintes dados:

Ferrugem-do-colmo e da-folha: Efetuou-se a avaliação dessas doenças causadas, respectivamente, por Puccinia graminis tritici e $P$. recondita, através de observação geral, em cada parcela, no colmo e nas folhas superiores das plantas, no estádio de início de maturação em condições naturais de infecçāo. Empregou-se a escala modificada de Cobb, para avaliação da resistência no Ensaio Internacionai de Ferrugem do Trigo de Primavera (International Spring Wheat Rust Nursery), de SCHRAM et al. (1974). Essa escala vai de 0 a $99 \%$ de área foliar infectada, complementada pelo tipo de reação: $S=$ suscetivel (uredossoro grande, coalescente, sem necrose e sem clorose); $M S=$ moderadamente suscetivel (uredossoro médio); $M=$ intermediário (diversos tipos de reação); $\mathrm{MR}=$ moderadamente resistente (uredossoro pequeno); $\mathrm{R}=$ resistente (uredossoro minúsculo, rodeado de áreas necróticas).

QUADRO 1. Análıses (1) das amostras compostas dos solos dos locals de instalação dos ensaios de linhagens e cultivares de trigo em 1984, 1985 e 1986

\begin{tabular}{|c|c|c|c|c|c|c|c|c|c|}
\hline \multirow{2}{*}{ Determinaçōes } & \multicolumn{3}{|c|}{ Capão Bonito } & \multicolumn{2}{|c|}{ Campinas } & \multicolumn{2}{|c|}{ Tatuí } & \multirow{2}{*}{$\begin{array}{c}\text { Maracaí } \\
1984\end{array}$} & \multirow{2}{*}{$\begin{array}{c}\text { Cruzália } \\
1985\end{array}$} \\
\hline & 1984 & 1985 & 1986 & 1984 & 1986 & 1984 & 1985 & & \\
\hline P. resina $\left(\mu \mathrm{g} / \mathrm{cm}^{3}\right)$ & 22 & 8 & 11 & 40 & 23 & 36 & 51 & 63 & 21 \\
\hline M.O. $(\%)$ & 4,1 & 3,5 & 3,0 & 3,1 & 3,2 & 2,1 & 2,8 & 4,3 & 5,4 \\
\hline $\mathrm{pH}(\mathrm{CaCl} 2)$ & 4,5 & 4,6 & 4,7 & 5,1 & 4,7 & 4,7 & 5,3 & 5,7 & 5,1 \\
\hline $\mathrm{K}\left(\mathrm{meq} / 100 \mathrm{~cm}^{3}\right)$ & 0,11 & 0,08 & 0,13 & 0,22 & 0,35 & 0,32 & 0,43 & 0,30 & 0,24 \\
\hline $\mathrm{Ca}\left(\mathrm{meq} / 100 \mathrm{~cm}^{3}\right)$ & 2,2 & 2,0 & 2,2 & 2,9 & 2,2 & 3,6 & 3,7 & 5,8 & 3,7 \\
\hline $\mathrm{Mg}\left(\mathrm{meq} / 100 \mathrm{~cm}^{3}\right)$ & 0,6 & 0,6 & 0,7 & 1,4 & 0,9 & 1,4 & 1,5 & 2,1 & 1,7 \\
\hline $\mathrm{H}+\mathrm{Al}\left(\mathrm{meq} / 100 \mathrm{~cm}^{3}\right)$ & 4,7 & 5,6 & 5,1 & 3,4 & 4,7 & 3,9 & 3,2 & 2,7 & 3,9 \\
\hline $\mathrm{S}\left(\mathrm{meq} / 100 \mathrm{~cm}^{3}\right)$ & 2,9 & 2,7 & 3,0 & 4,5 & 3,5 & 5,3 & 5,6 & 8,2 & 5,6 \\
\hline$T\left(\mathrm{meq} / 100 \mathrm{~cm}^{3}\right)$ & 7,6 & 8,3 & 8,1 & 7,9 & 8,2 & 9,2 & 8,8 & 10,9 & 9,5 \\
\hline$V(\%)$ & 38 & 33 & 37 & 57 & 43 & 58 & 64 & 75 & 59 \\
\hline
\end{tabular}

(1) Efetuadas pela Seção de Fertilidade do Solo e Nutrição de Plantas, Instituto Agronômico. 
Helmintosporiose: Procedeu-se à avaliação de manchas foliares causadas por Helminthosporium sp., em planta adulta, em condiçōes naturais de infecção, empregando-se uma escala (MEHTA, 1978), de 0 a $99 \%$ de área infectada: zero é considerado imune; 1 a $5 \%$, resistente; 6 a $25 \%$, moderadamente resistente; 26 a $50 \%$, suscetivel, e 51 a $99 \%$, altamente suscetivel.

Oidio: A avaliaçāo dessa doença, causada pelo fungo Erysiphe graminis sp. tritici, foi feita de maneira identica à da helmintosporiose.

Ciclo da emergência ao florescimento: Fazendo-se contagens por parcela individual do número de dias da emergência das plântulas ao pleno florescimento.

Ciclo da emergência à maturação: Efetuando-se contagens por parcela individual do número de dias da emergência das plântulas à maturação fisiológica.

Plantas acamadas: Considerando a porcentagem de plantas acamadas em cada parcela, por avaliação visual próxima à época de maturação.

Altura das plantas: Medindo no campo, na época de maturação, a distância, ern centímetros, do nivel do solo ao ápice da espiga, excluindo as aristas, e levando em consideração a média de diferentes pontos de cada parcela.

Comprimento da espiga: Considerando o comprimento médio, em centímetros, de vinte espigas tomadas ao acaso de cada parcela, com exclusão das aristas.

Número de espiguetas: Considerando o número médio de espiguetas de vinte espigas tomadas ao acaso de cada parcela.

Grãos por espiga: Considerando o número médio de grãos contados em vinte espigas colhidas ao acaso de cada parcela.

Grãos por espigueta: Calculando, pela divisão do número total de grãos de vinte espigas, coletadas ao acaso de cada parcela, pelo número total de suas espiguetas.

Produção de grãos: Pesando, em gramas, a produção total de grãos de cada parcela, a qual foi transformada em quilograma/hectare.

As sementes das linhagens e cultivares estudados foram remetidas ao Centro Nacional de Pesquisa de Trigo da EMBRAPA, Passo Fundo (RS), para identificação, quanto à resistência em estádio de plântula, em condiçōes de casa de vegetação, a algumas raças de $P$. graminis tritici (G-15, G-17, G-18, G-19, G-20 e G-21) e de $P$. recondita (B-26, B-27, B-29 e B-30), de ocorrência comum no Brasil (BARCELLOS, 1986, e COELHO, 1986).

As plântulas das linhagens e dos cultivares foram testadas para tolerância a $0,2,4,6,8$ e $10 \mathrm{mg} /$ litro de $\mathrm{Al}^{3+}$ em soluções nutritivas, conforme CAMARGO \& OLIVEIRA (1981); CAMARGO et al. (1980) e MOORE et al. (1976). 
O delineamento estatístico empregado foi de blocos ao acaso com parcelas subdivididas, sendo as parcelas compostas por seis concentraçōes de aluminio e as subparcelas, pelos genótipos de trigo. Foram feitas duas repetições para cada solução de tratamento. Os dados foram analisados, considerando-se a média de comprimento da raiz primária central das vinte plântulas de cada genótipo, em 72 horas de crescimento nas soluçōes nutritivas completas sem aluminio, que se seguiu a 48 horas de crescimento nas soluções de tratamento contendo seis diferentes concentraçōes de alumínio.

\section{RESULTADOS E DISCUSSÃO}

As produções médias de grãos transformadas em quilograma/hectare das linhagens e dos cultivares BH-1146, IAC-5 e Alondra-S-46, estudados em 1984-86, em diferentes regiōes paulistas, encontram-se no quadro 2. Foram detectados efeitos significativos para cultivares e linhagens na análise estatística dos experimentos, considerados sẹparadamente, fazendo exceção os experimentos conduzidos em Capão Bonito (1985) e Campinas (1986).

Os ensaios de Capão Bonito, 1984-86, considerados em conjunto, mostraram, pela análise de variância efeitos significativos para anos, linhagens e interaçāo linhagem $x$ ano.

Através do teste de Tukey aplicado ao nivel de $5 \%$ para a comparaçāo das médias de produção de grãos dos cultivares e linhagens desses ensaios nos três anos, em condição de solo ácido (Quadro 1), com percentagem de saturaçāo por bases (variando de 33 a $38 \%$ ), verificou-se que o ' $\mathrm{BH}-1146$ ', tolerante à toxicidade de $\mathrm{Al}^{3+}$ (CAMARGO \& OLIVEIRA, 1981) apresentou a maior produção de grāos, somente diferindo, porém, das linhagens 1,2, 3, 17 e 18 e do cultivar Alondra-S-46, de moderada suscetibilidade ao $\mathrm{Al}^{3}+$ (CAMARGO \& OLIVEIRA, 1981).

$A$ análise de variancia dos dois experimentos de Campinas, com irrigação por aspersão, tomados em conjunto, mostrou efeitos significativos para linhagens e anos, e não-significativos para a interação linhagem $x$ ano.

Nesses ensaios, destacaram-se as linhagens 4 (IRN 33-70 $\times$ IAC-5), 9 [IRN 526-63 (2) x Pel 14933-64] e 13 (IRN 641-70 x BH-1146), que deu origer à $\mid A C-171$, quanto à produção de grãos, diferindo ao nivel de $5 \%$ da linhagem $1 \mathrm{e}$ do cultivar Alondra-S-46.

A análise de variância dos dois experimentos plantados em Tatui, nos anos de 1984 e 1985, considerados em conjunto, apresentou efeitos significativos para linhagens, anos e interação linhagem $x$ ano.

Neles, a linhagem $8=$ Super $X \times[R \times I R N ~ 471-63(5)]$, que deu origem à IAC-228, mostrou a maior produção de grãos, diferindo das linhagens 1 e 3 . 


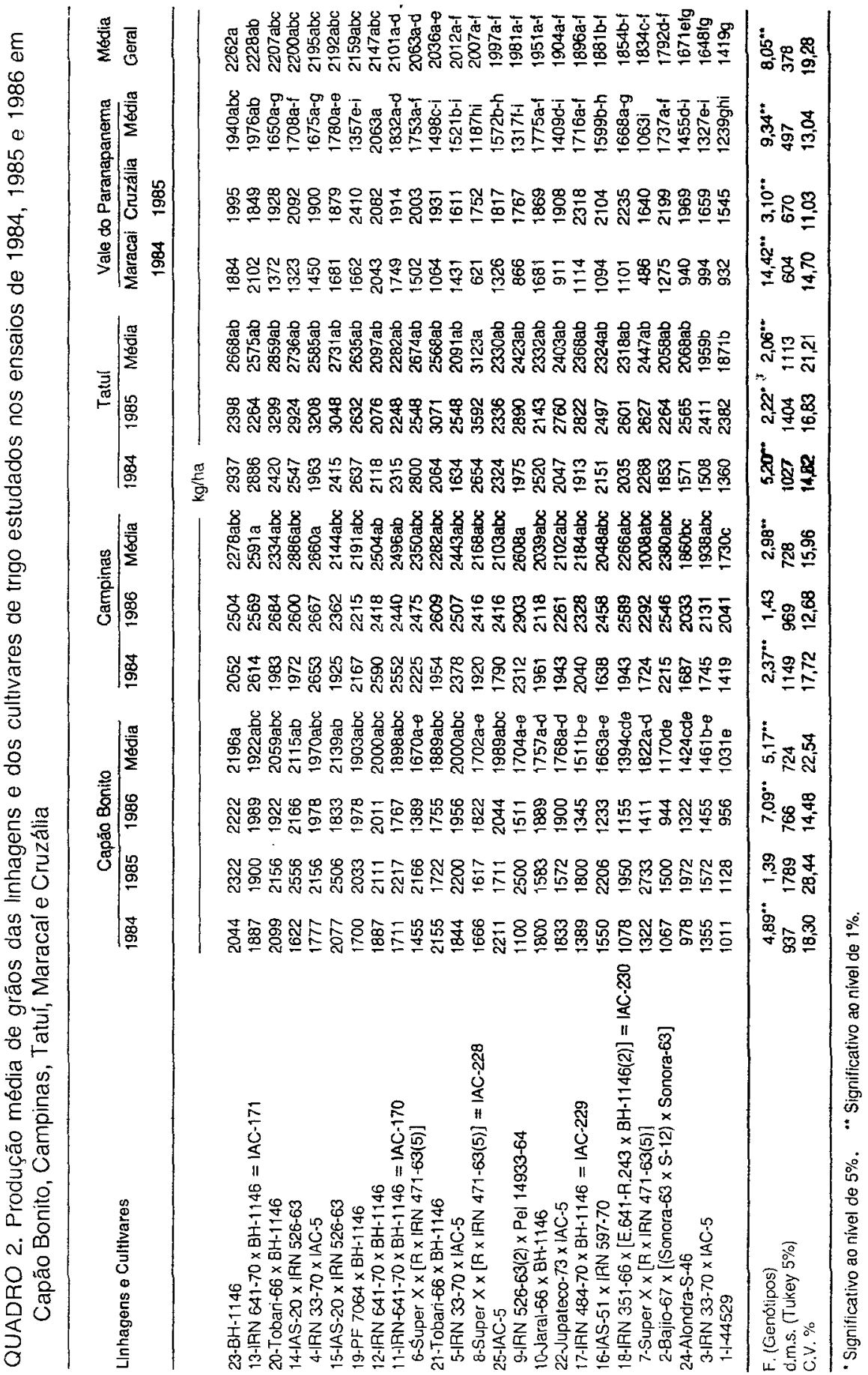


A análise de variância dos dois ensaios do Vale do Paranapanema em condição de sequeiro exibiu efeitos significativos para linhagens, anos e interação linhagem $x$ ano.

A linhagem 12 (IRN $641-70 \times \mathrm{BH}-1146$ ) foi a mais produtiva, diferindo das linhagens $1,3,5,7,8,9,16,19,21$ e 22 e dos cultivares controles Alondra-S46 e IAC-5.

Analisando-se em conjunto os nove ensaios, verificaram-se efeitos altamente significativos para genótipos, ensaios e interação genótipos $x$ ensaio. Pelo teste de Tukey, o cultivar $\mathrm{BH}-1146$ e as linhagens 20,14 e 13 foram os mais produtivos, diferindo das linhagens 1, 2 e 3 e do cultivar Alondra-S-46.

As porcentagens máximas de área infectada pelos agentes causais da ferrugem-do-colmo e da-folha, oídio e helmintosporiose, e os tipos de reação às duas ferrugens, nas linhagens e cultivares estudados nos nove experimentos, encontram-se no quadro 3.

Em condição de campo, as linhagens 1, 2, 8 e 17 mostraram-se mais resistentes ao agente causal da ferrugem-do-colmo, com uma porcentagem máxima de área infectada igual ou inferior a 20. As linhagens e cultivares mais suscetiveis exibiram uma porcentagem máxima de área infectada igual a 80 . As linhagens 1 e 2, apesar das produçōes significativamente inferiores às do cultivar $\mathrm{BH}-1146$, foram mienos suscetíveis à ferrugem-do-colmo: poderão, portanto, ser aproveitadas em cruzamentos no programa de melhoramento.

Em relação à ferrugem-da-folha, todos os genótipos mostraram reaçōes de suscetibilidade, porém as linhagens $1,5,8$ e 18 e os cultivares $\mathrm{BH}-1146$ e IAC-5 exibiram menor porcentagem de área foliar infectada (30). Esses resultados demonstraram a necessidade de incorporar resistência genética mais estável aos novos cultivares de trigo.

As linhagens 3, 6 e 15 exibiram moderada resistência ao oídio, quando comparada com o cultivar Alondra-S-46, que se mostrou altamente suscetivel.

Entre os genótipos, destacou-se quanto à resistência à helmintosporiose, a linhagem 8 , com $20 \%$ de área foliar infectada. Nas mesmas condiçỏes as linhagens mais suscetiveis mostraram $60 \%$.

As reaçōes das linhagens e cultivares (estádio de plântula) a Puccinia graminis f. sp. tritici e P. recondita, em casa de vegetação, encontram-se no quadro 4. As linhagens 7 e 8 e o 'Alondra-S-46' apresentaram-se resistentes às seis raças do agente causal da ferrugem-do-colmo. As linhagens 17 e 18 mostraram-se resistentes a cinco raças desse agente causal. Esses genótipos também foram os mais resistentes em condição de campo, à exceção da linhagem 18, que mostrou um grau máximo de infecção igual a $60 \mathrm{~S}$, em condição de campo. Apesar de resistente a cinco raças, mostrou-se suscetivel à G-19, uma das prevalecentes nos últimos anos no Estado de São Paulo (COELHO, 1983). As linhagens $10,11,14,15,19$ e 22 e os cultivares BH-1146 e IAC-5 foram suscetiveis em es- 


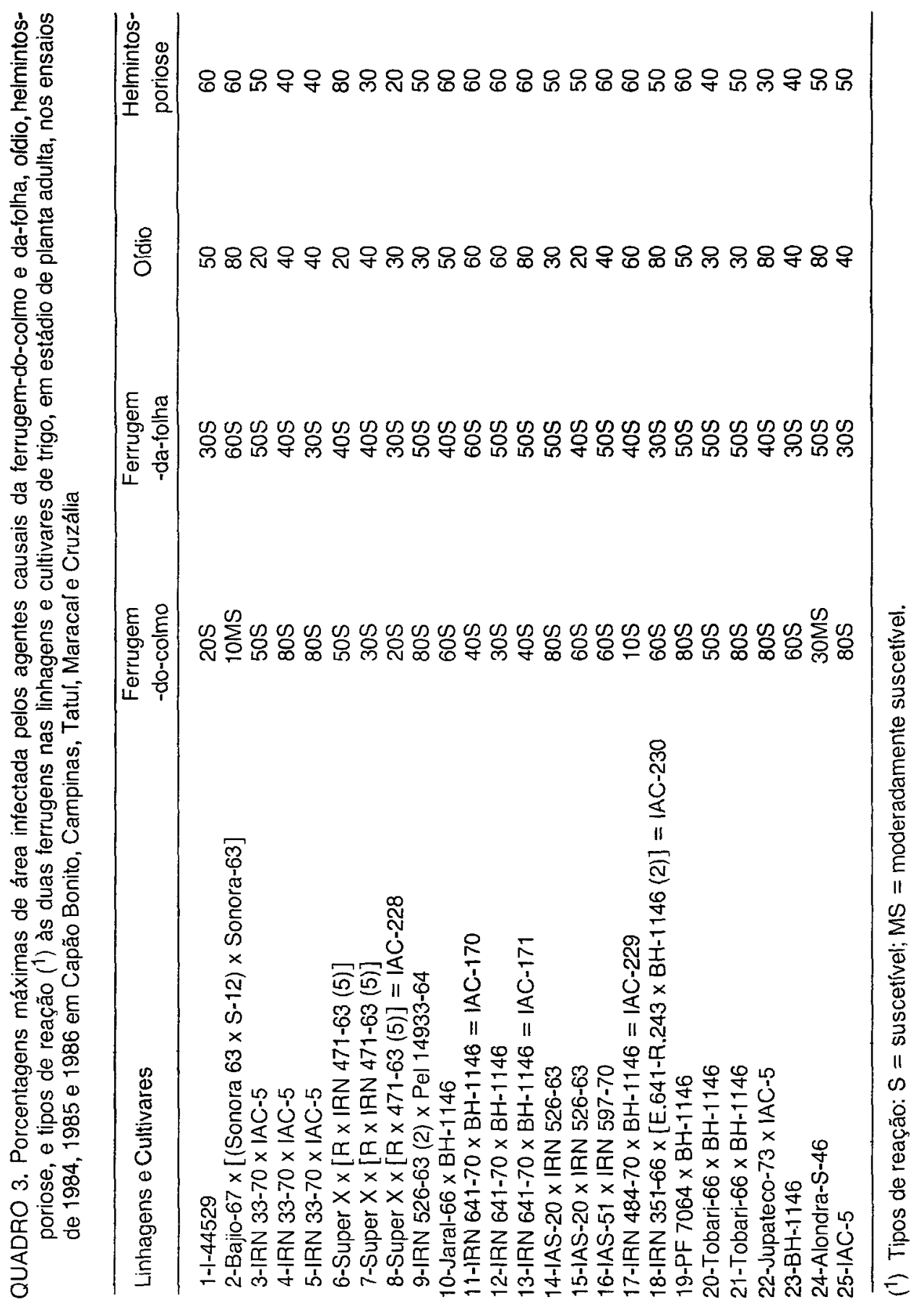


tádio de plântula às seis raças testadas: em condição de campo, exibiram grande suscetibilidade, com um grau máximo de infecçao variando de 605 a $80 \mathrm{~S}$. Em relação à resistência às raças de $P$. recondita (femugem-da-folha), todos os genótipos mostraram suscetibilidade a uma raça, pelo menos, entre as quatro testadas. Apesar de a maioria das linhagens não ter sido testada para as quatro raças de ferrugem-da-folha, verificou-se que a 18 apresentou resistência a duas delas (B-26 e B-27), entre três testadas. Essa linhagem também exibiu menor grau máximo de infecçāo (30S) em condição de campo.

O ciclo, em dias, da emergência ao florescimento e da emergência à maturação; a porcentagem de plantas acamadas; a altura da planta; o comprimento da espiga; o número de grãos por espiga e por espigueta; o número de espiguetas e o peso de cem grãos das linhagens e cultivares estudados nos nove ensaios encontram-se no quadro 5.

A linhagem 6, com 104 dias da emergência à maturação, foi considerada como a mais precoce, não diferindo estatisticamente, porém, das linhagens $1,2,3,10,11,12,13,14,15,16,17,18$ e 19 e do cultivar BH-1146. A linhagem 7 foi considerada como de ciclo médio a tardio, pois levou 126 dias da emergência à maturação, não diferindo significativamente das linhagens 4, 8, 9, 20,21 e 22 e dos cultivares controles IAC-5 e Alondra-S-46. A linhagem 5, com 115 dias, foi considerada como de ciclo médio.

Todos os genótipos exibiram diferentes graus de acarramento, sendo mais resistentes as linhagens $2,3,4,7,8,18,20$ e 21 e o cultivar Alondra-S-46. As linhagens 6, 10, 14, 15 e 19 mostraram maior sensibilidade ao acamamento; assim, não seriam indicadas para cultivo com irrigação por aspersāo, pois suas produções poderiam ser prejudicadas pelo acamamento.

As linhagens 2, 7, 8 (IAC-228), 17 (IAC-229) e 18 (IAC-230), consideradas de porte baixo, não diferiram do cultivar Alondra-S-46, mas foram estatisticamente diferentes dos cultivares de porte alto BH-1146 e IAC-5. A linhagem 5 apresentou a maior altura das plantas, não diferindo estatisticamente das linhagens $4,6,10,14,15,19,20,21$ e 22 e dos cultivares BH-1146 e IAC-5.

As linhagens que apresentaram espigas mais compridas, 4 e 5, não diferiram entre si, mas mostraram-se estatisticamente diferentes das demais linhagens e cultivares. Essas duas também exibiram o maior número de grãos por espiga, só nāo diferindo das linhagens 3, 7, 8 e 21 e do cultivar IAC-5. As linhagens 4 e 5 , originárias do cruzamento IRN 33-70 x IAC-5, constituem germoplasmas de grande valor, num programa de melhoramento do trigo como fontes genéticas visando ao aumento das características comprimento e número de grãos por espiga.

As linhagens 3, 11 e 12 apresentaram o maior nümero de grãos por espigueta, isto é, maior fertilidade da espiga, só não diferindo das linhagens $4,5,6$, $7,8,13,17$ e 18 e do cultivar Alondra-S-46. 


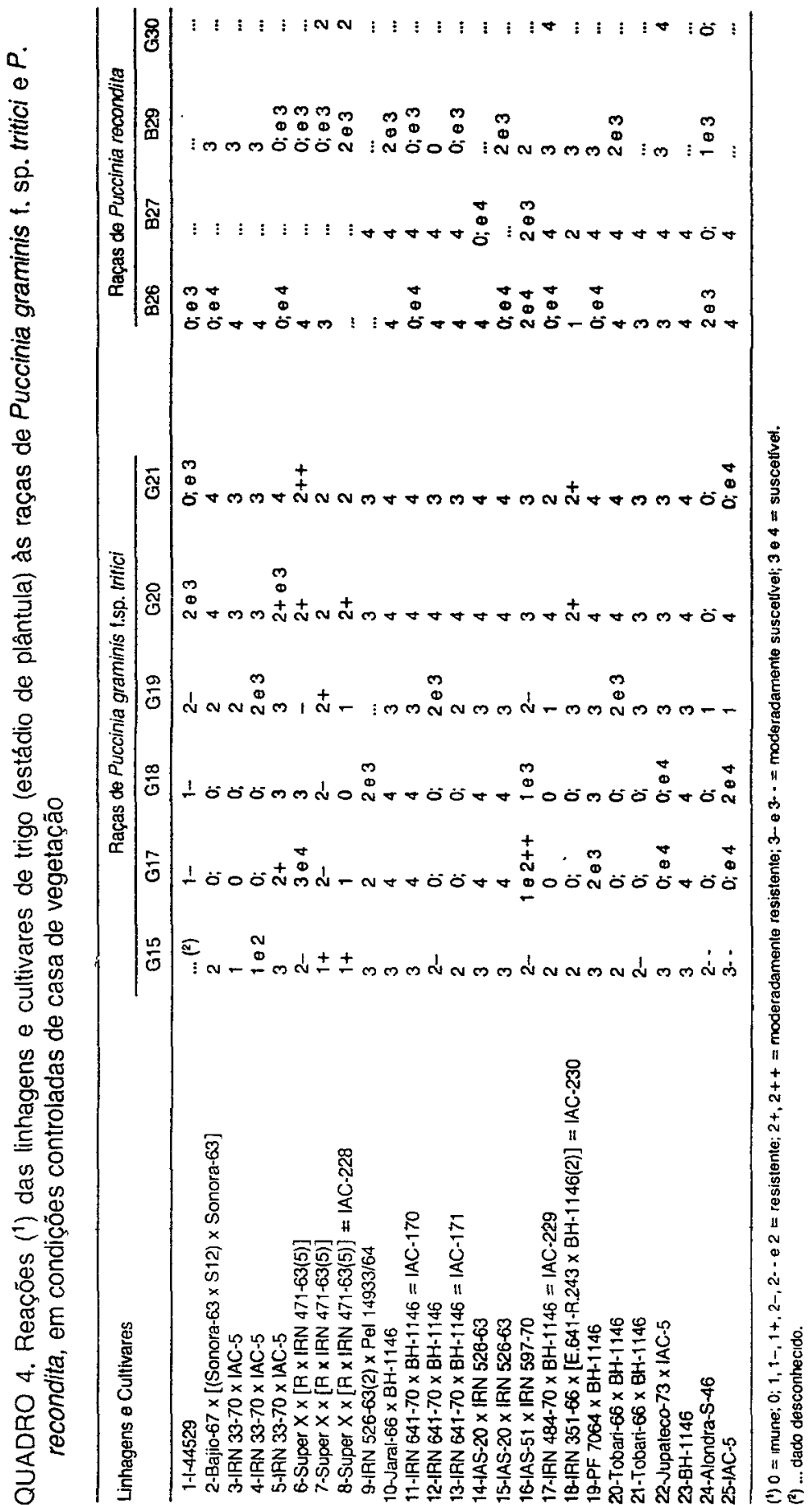




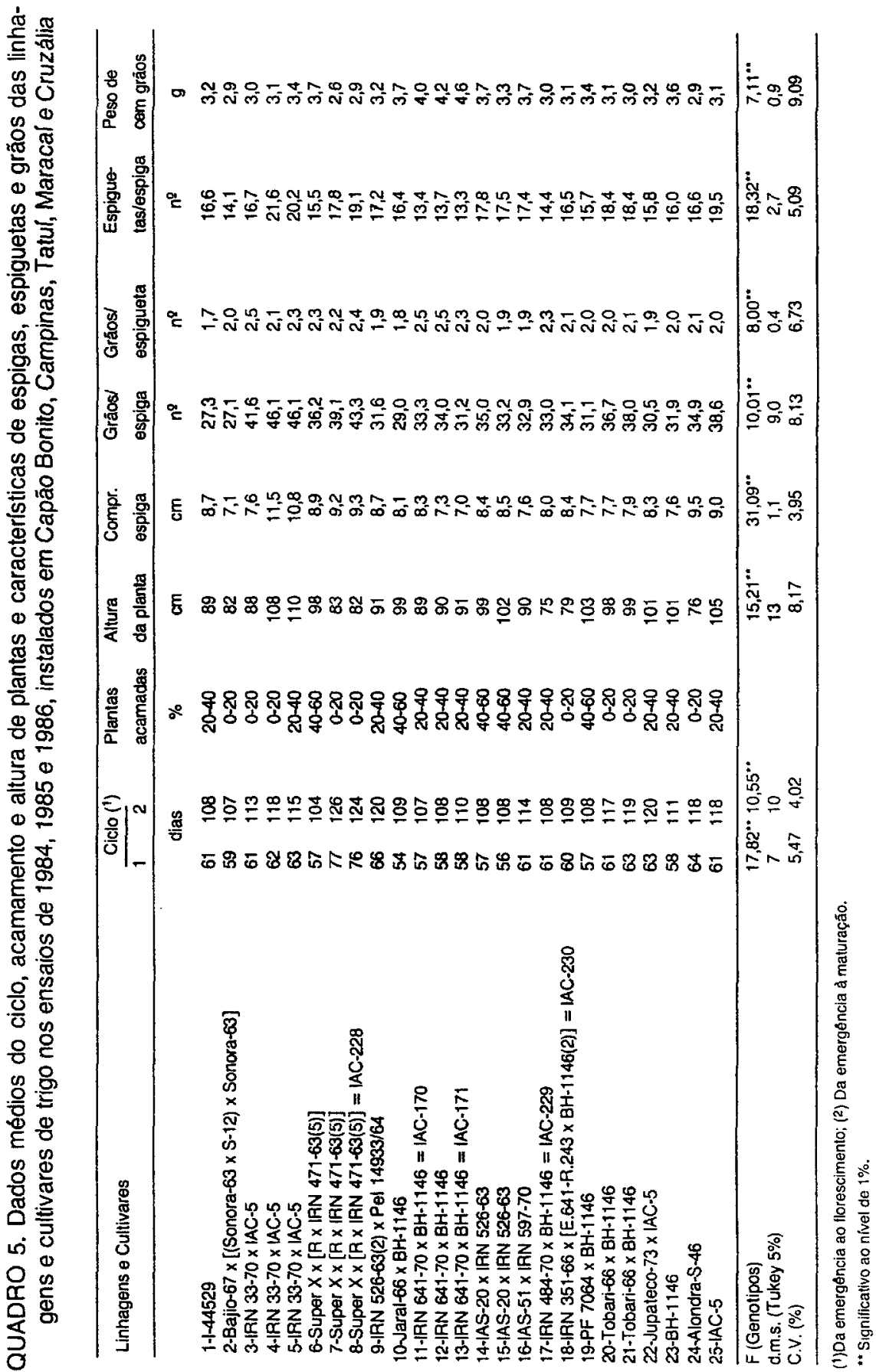




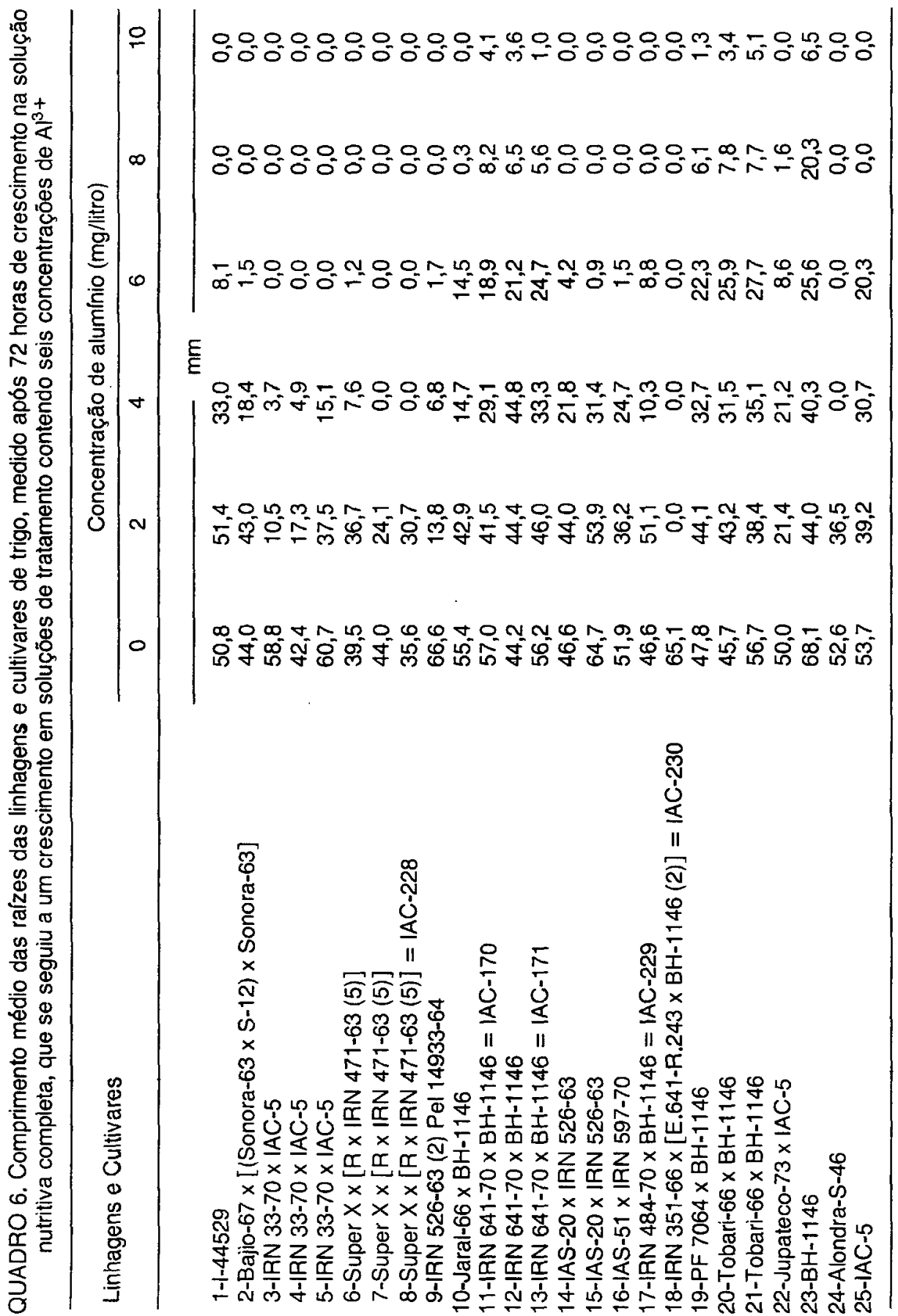


A linhagem 4, com o maior número de espiguetas por espiga, só não diferiu estatisticamente das linhagens 5 e 8 e do cultivar IAC-5.

A linhagem 13 (IAC-171) apresentou os grãos mais pesados, não diferindo significativamente apenas das linhagens $6,10,11,12,14$ e 16. A IAC-171 pode ser considerada uma fonte genética de valor para aumentar o peso de cem grãos em um programa de cruzamentos visando à transferência desse fator para outros germoplasmas.

O comprimento médio das raízes de todas as linhagens e cultivares de trigo, medido após 72 horas de crescimento nas soluçōes nutritivas completas que se seguiu a um crescimento de 48 horas nas soluçōes de tratamento contendb seis diferentes concentraçōes de alumínio, encontram-se no quadro 6.

À concentração de $2 \mathrm{mg} /$ /litro de $\mathrm{Al}^{3+}$, a linhagem 18 (IAC-230) foi sensivel e as demais, tolerantes.

As linhagens 7 e 8 e o cultivar Alondra-S-46 exibiram sensibilidade quando se empregaram soluções com $4 \mathrm{mg} /$ litro, sendo, portanto, considerados como moderadamente sensiveis.

As linhagens 3,4 e 5 , tolerantes a $4 \mathrm{mg} /$ litro de $\mathrm{Al}^{3+}$, demonstraram sensibilidade à presença de $6 \mathrm{mg} /$ litro de $\mathrm{Al}^{3+}$ nas soluçōes de tratamento, sendo consideradas moderadamente tolerantes.

As linhagens $1,2,6,9,14,15,16$ e 17 e o cultivar IAC-5 foram sensíveis a $8 \mathrm{mg} /$ litro de $\mathrm{Al}^{3+}$, porém tolerantes na presença de $6 \mathrm{mg} /$ litro de $\mathrm{Al}^{3+}$, sendo, portanto, considerados como tolerantes à toxicidade de $\mathrm{Al}^{3+}$.

O cultivar $\mathrm{BH}-1146$ e as linhagens $11,12,13,19,20$ e 21 mostraram-se como tolerantes, mesmo quando se adicionaram $10 \mathrm{mg} /$ litro de $\mathrm{Al}^{3+}$ nas soluções de tratamento. Esses germoplasmas foram considerados muito tolerantes.

\section{CONCLUSÕES}

1) Em condição de sequeiro, o cultivar $\mathrm{BH}-1146$, tolerante ao alumínio tóxico, de porte alto, destacou-se quanto à produção de grãos em solos ácidos (porcentagem de saturação por bases, V, entre 33 e 38\%) de Capáo Bonito, enquanto a linhagem 12 , tolerante ao aluminio, de porte médio, foi a mais produtiva em solos de moderada a alta fertilidade ( $V$ entre 59 e $75 \%$ ).

2) Em condição de irrigação, as linhagens 4,9 e 13, de porte médio a alto, e com moderada a alta tolerância ao alumínio tóxico, apresentaram a maior produção em Campinas, e a linhagem 8 , de porte semi-anão, moderadamente sensivel ao $\mathrm{Al}^{3+}$, foi a mais produtiva em Tatuí.

3) Em relação à produção de grãos, considerando-se a média dos nove experimentos, destacaram-se, por ordem decrescente, o cultivar $\mathrm{BH}-1146$ e as linhagens 13, 20 e 14. 
4) As linhagens 7 e 8 e o cultivar Alondra-S-46 mostraram resistência às seis raças do agente causal da ferrugem-do-colmo em estádio de plântula, em casa de vegetação, e as linhagens 17 e 18, a cinco. Em condição de campo, no estádio de planta adulta, apresentaram menor área infectada por essa doença as linhagens 1, 2, 7, 8, 12 e 17 e o cultivar Alondra-S-46. As linhagens 10, 14, 15, 18, 19 e 22 e os cultivares BH-1146 e IAC-5 mostraram-se suscetiveis à doença, indicando a necessidade da incorporação de resistência às raças prevalecentes do agente causal da ferrugem do colmo.

5) As linhagens 1, 5, 8 e 18 apresentaram-se com menores porcentagens, de área infectada pelo agente causal da ferrugem da folha, em condiçāo de infecção natural, em estádio de planta adulta.

6) As linhagens 3,6 e 15 destacaram-se quanto à resistência ao oídio e a 8, à helmintosporiose.

7) As linhagens $2,7,8,17$ e 18 e o cultivar Alondra-S-46 mostraram plantas significativamente mais baixas que 0 ' $\mathrm{BH}-1146$ ' e o 'IAC-5'.

8) A linhagem 18 foi sensivel à toxicidade de $\mathrm{Al}^{3+}$. As linhagens 7 e 8 e o cultivar Alondra-S-46 foram moderadamente sensiveis; as linhagens 3,4 e 5 mostraram-se moderadamente tolerantes; as linhagens $1,2,6,9,14,15,16$ e 17 e o cultivar IAC-5, tolerantes, e as linhagens 11, 12, 13, 19, 20 e 21 e o 'BH-1146', muito tolerantes.

\section{SUMMARY}

\section{WHEAT BREEDING. XVIII: EVALUATION ON INBRED LINES FOR THE STATE OF SĀO PAULO, BRAZIL}

Twenty two inbred lines from the wheat breeding program at the Instituto Agronômico of Campinas plus the cultivars BH-1146, Alondra-S-46 and $\mathrm{IAC}-5$ were evaluated in field experiments carried out at Campinas, Capão Bonito and Tietê Experimental Stations, and at two farms located in the Paranapanema Valley, during the period 1984-1986. Grain yield, plant height, number of days from emergence to flowering and from emergence to maturation, percentage of lodged plants, head length, number of grain per spike and per spikelet, number of spikelets, weight of 100 grains, and resistance to stem and teaf rusts, to Helmintiosporium sp. and to powdery mildew were evaluated under field conditions. Tests of resistance to stem and leaf rusts and to aluminum tolerance, were made in greenhouse and laboratory, respectively. At Capāo Bonito and Paranapanema Valley the cultivar $\mathrm{BH}-1146$ and the line 12 showed good grain yield in upland conditions. The lines 4,9 and 13 at Campinas and the line 8 at Tatui presented good productivity under sprinkler irrigation. The cultivar $\mathrm{BH}-1146$ and the lines 13,20 and 14 exhibited the highest grain yieid considering the average of the nine expe- 
riments. The lines $2,7,8,17$ and 18 and the cultivar Alondra-S-46 exhibited semidwarf type when compared to the tall cultivars BH-1146 and IAC-5. In relation to stem rust, the lines 7 and 8 and the cultivar Alondra-S-46 showed resistance at seedling stage to the six races and the lines 17 and 18 were resistant to five races, under greenhouse conditions. The lines 1, 2, 7, 8, 12 and 17, plus the cultivar Alondra-S-46 presented resistance to stem rust under field conditions. The lines $1,5,8$ and 18 exhibited low levels of leaf rust under natural infection out in the field. The lines $11,12,13,19,20$ and 21 as well as ' $\mathrm{BH}-1146$ ' were tolerant to the presence of $10 \mathrm{mg} / \mathrm{liter}$ of $\mathrm{Al}^{3+}$ in the nutrient solution.

Index terms: wheat, Triticum aestivum L., grain yield, plant height, stem and leat rusts, tolerance, aluminum toxicity.

\section{AGRADECIMENTOS}

Os autores agradecem ao Centro Nacional de Pesquisas de Trigo (EMBRAPA) os testes de resistência às ferrugens-do-colmo e da-folha em casa de vegetação.

\section{REFERÊNCIAS BIBLIOGRÁFICAS}

ALCOVER, M. Melhoramento de variedades de trigo em São Paulo. In: ENCONTRO SOBRE TRITICULTURA. Campinas, Coordenadoria de Assistência Técnica Integral, 1971. 26p.

BARCELLOS, A.L. Ferrugem da folha do trigo no Brasil em 1984 e 1985. Ocorrência e virulência: In: REUNIÄO DA COMISSĀO NACIONAL DE PESQUISA DE TRIGO, 14., Londrina; 1986. Passo Fundo, EMBRAPA, Centro Nacional de Pesquisa de Trigo, 1986. p.117-131.

CAMARGC, C.E.O. Estudo de variedades de trigo para o Estado de São Paulo. Piracicaba, ESALQ, 1972. $102+34$ p. Tese (Doutoramento)

\& FELÍCIO, J.C. Melhoramento genético do trigo no Estado de São Paulo. $O$ Agronômico, Campinas, 38(3):213-227, 1986.

; ;REITAS, J.G.; BARRCS, B.C., CASTRO, J.L. \& SABINO, J.C. Melhoramento do trigo. XII. Comportamento de novas linhagens e cultivares no Estado de São Paulo. Bragantia, Campinas, 44(2):669-685, 1985.

; KRONSTAD, W.E. \& METZGER, R.J. Parent-progeny regression estimates and associations of height level, with aluminum toxicity and grain yield in wheat. Crop Science, 20:355-358, 1980.

\& OLIVEIRA, O.F. Tolerância de cultivares de trigo a diferentes níveis de alumínio em solução nutritiva e no solo. Bragantia, Campinas, 40:21-31, 1981.

CCELHO, E.T. Avaliação de resistência a ferrugem do colmo dos cultivares dos ensaios regionais de rendimento de variedades de trigo do CONE SUL (ERCOS). In: REUNIÄO DA COMISSĀO NACIONAL DE PESQUISA DE TRIGO, 14., Londrina, 1986. Passo Fundo, EMBRAPA, Centro Nacional de Pesquisa de Trigo, 1986. p.101-110. 
FELICIO, J.C.; BARROS, B.C.; CAMARGO, C.E.O. \& BÄR W.H. Maracaf (IAC-17) e Xavantes (IAC-18): cultivares de trigo para o Estado de São Paulo. Bragantia, Campinas, 42:15-25, 1983.

HANSON, H.; BORLAUG, N.E. \& ANDERSON, R.G. Wheat in the third world. Boulder, Colorado, Westview Press, 1982. 174p.

JUNQUEIRA, P.C. \& SILVA, J.R. Perspectivas da cultura do trigo na Regiāo Centro-Sul. Relatório apresentado pelo Instituto de Economia Agricoia ao Grupo de Trabalho de Trigo do Estado de São Paulo do Ministério da Agricultura, 1986. 18p. (mimeografado)

MEHTA, Y.R. Doenças do trigo e seu controle. São Paulo, Ceres, 1978. 190p.

MOORE, D.P.; KRONSTAD, W.E. \& METZGER, R.J. Screening wheat for aluminum tolerance. In: WORKSHOP ON PLANT ADAPTATIONS TO MINERAL STRESS IN PROBLEM SOILS, Beltsville, Maryland, 1976. Proceedings. p.287-295.

SCHRAM, W.; FULCO, W.S.; SOARES, M.H.G. \& ALMEIDA, A.M.P. Resistência de cultivares de trigo em experimentação ou cultivo no Rio Grande do Sul às principais doenças fủngicas. Agronomia Sulriograndense, Porto Alegre, 10:31-39, 1974. 